\title{
Numerical flow analysis and heat transfer in smooth and grooved tubes
}

\author{
S. Jamshed, S. R. Qureshi \& M. S. Khalid \\ PNEC, National University of Sciences and Technology, Pakistan
}

\begin{abstract}
This paper discussed the heat transfer enhancement due to groove formation in a metallic tube. A set of three tubes, namely, the simple metallic tube (SMT), the straight groove tube (SGT) and the helically grooved tube with 12-inch pitch (GT12) were numerically studied. The tube data and experimental findings on it were extracted from published article by Arunrat. Performance criteria through CFD was based on the heat transfer via Nusselt number as well as the friction factor. For the heat transfer performance, it was evaluated with the thermal performance factor given by $\left(\mathrm{Nu} / \mathrm{Nu}_{\mathrm{s}}\right) /\left(\mathrm{f} / \mathrm{f}_{\mathrm{s}}\right)$, whereas $\mathrm{Nu}$ is the Nusselt number and $f$ is the friction factor and subscript ' $s$ ' is for the smooth tube. Two turbulence models were used, viz, k-epsilon realizable and k-omega Shear Stress Transport. Between the two turbulence models tested and the given range of Reynolds number, it was found that $\mathrm{k}-\omega \mathrm{SST}$ is the most suitable candidate for this range of Reynolds number due to its closeness to the experimental data both in the case of the Nusselt and friction factor. Among the three tubes tested and making the simple metallic tube (SMT) the baseline, the GT12 performed better and has performance factor better than the other two at most of the Reynolds numbers. Keywords: heat transfer, CFD, groove tubes, Nusselt number, friction factor.
\end{abstract}

\section{Introduction}

Heat transfer enhancement in heat exchangers has been the subject of much research since its beginning. The technology betterment and new horizons in engineering in every era made man to create complex structures. Initial designs of heat exchangers consisted of mainly shell and tube. Then with the improvement of machines to manufacture them as well as the Computer Aided Design and Manufacturing $(\mathrm{CAD} / \mathrm{M})$, it was possible to make complex heat exchangers 
designs. It was evident in engineering that the performance of heat exchangers can be enhanced by increasing the surface area of the surface exposed to fluid. Fin design became so popular in this regard. To test the performance of finned tubes, in the middle of the 20th century, there were two methods available, experiment and analytical. Also, in the last decades of the century, research was being conducted by utilizing numerical approach in finned-tube design where the concept of heat enhancement was gaining popularity [1]. Also, numerical techniques like Computational Fluid Dynamics (CFD) was matured enough to work on these enhanced surfaces.

The research work on enhancement in heat transfer began within the mid1950s. However, with the technological advancements in manufacturing the notable works of Webb, Bergles and Adrian Bejan are mentionable. Webb et al. [2] published a paper in 1971, on the concept of repeated rib roughness that was scientific achievement in the area of enhancement of heat transfer. Correlations were established and were analogous to the results of experiments performed by previous researchers like Nikuradse, who did the research on plain pipes with sand-grain roughness. Webb concluded the research that the results of ribroughened surfaces are analogous to the heat-momentum transfer analogy. In 1999, a paper was published bv Jensen and Vlakancic [3] on studying the effect of fin height and depth within the tube. Reynolds number based on the internal (finless) diameter of the tube was 10,000 to 90,000 . The focus was to establish criteria for $\mathrm{f}$ and $\mathrm{Nu}$ at various fin heights. For high fins, flow becomes fully turbulent at $\operatorname{Re} \sim 10000$, while for micro fins there is long lasting transitional flow up to Reynolds 20,000. For small fin tubes, the friction factor curve experiences long transitional period before becoming fully turbulent at $\operatorname{Re} \sim 20,000$ and also during the transitional period the friction factor is independent of Reynolds number. In 2000, Webb et al. [4] had a paper published in which they discussed the heat transfer and friction in helical grooved tubes. The tubes have heat transfer surfaces on both sides. The inner side had the helical formation of the fins. Reynolds number was 20000 to 80000 . The purpose of this paper was to develop multiple regression correlation for Colburn $\mathrm{j}$ factor $\left(\mathrm{StPr}^{2 / 3}\right)$ and friction factor. These correlations over predicted the friction factor 0 to 15 percent and predicted the j-factor within ten percent of the experiment. The conclusion was based on the statement that the tested tubes were successful in depicting the behaviour of roughened surfaces (due to enhancement provided by local flow separation within the ribs) as well as internal finned tubes. Zdaniuk et al. [5] conducted flow investigation in helically finned-tubes and found heat transfer coefficients and friction factor in 8 helically finned-tube and one smooth tube. Liquid water was used as working fluid and Reynolds number tested range was 12000 to 60000 . The results when compared with the results of experimental work by Webb et al. [4] were in good estimate within the prediction errors between 30 and $40 \%$.

Grooved and finned geometries were also examined from numerical point of view. Liu and Jensen [6] studied the effect of various fin models in a tube. The effects of height, number of fins, fin width and helix angle were numerically examined along with the different shapes of fin profile. Reynolds number was between 10,000 and 70,000. It was found that, for some geometric conditions, the 
performance variation is insignificant between rectangular and triangular fins while for the round one, friction factors and Nusselt number were under-predicted (about 7-10\%) than rectangular fins geometry. Kim et al. [7] also studied the fin geometries from numerical point of view. A periodic portion was modeled to reduce the computational expense. A Stable Finite Element Method (SFEM) model technique was utilized to model the flow, and the problem was analyzed to see the fluid flow and heat transfer effects. With the numerical analysis it was found that the interfin region is not a function of fin height rather depends upon Reynolds number. Also great deal of similarity was observed in heat transfer in case of both fin heights irrespective of tube parameters.

Jasinski [8] performed analysis using CFX commercial code. Constant wall heat flux and fully developed 3D profile was applied as boundary condition. The influence of the helical angle of micro fins on heat transfer and flow was tested. The value of the helical angle was also varied and analyzed. The influence of entropy generation with helical angle was tested and it was found that minimum entropy trend was maximum in the 70-degree helical tube and occur around 60k Reynolds number. Aroonrat et al. [9] has determined the Nusselt number and the friction factor for Reynolds number range 4000 to 10000. Although this Reynolds number range is found to be low as compared to the literature seen above, the author has not explicitly mentioned the reason for this low values. The effect of the most pronounced heat transfer was on $\mathrm{Nu}$ on tube with the largest helix angle $\left(60^{\circ}\right)$ with the least pitch of 0.5 inches. This performance also flashed in the friction factor curve.

In this paper the author is reproducing the results by Arunrat for the three geometries, viz, plain tube, the straight groove tube and the helical groove tube with a 4-degree helix angle. The results have been compared using two turbulence models and explained. The thermal efficiency index has also been computed.

\section{Experimental work}

The experiment that was performed was by Aroonrat et al. [9]. This was done basically focusing on the grooved tubes. A number of tubes with variable helix angles have been used. The tube was $2 \mathrm{~m}$ in length and was made of Steel MS 304. Since the thermocouples were mounted in a short region as mentioned in Figure 1, only that portion has been modeled in simulation. T-type thermocouples were used to compute the temperature at the test section ends but also along the length of the test section. The groove tube terminology is embedded in the sketch of Figure 2.

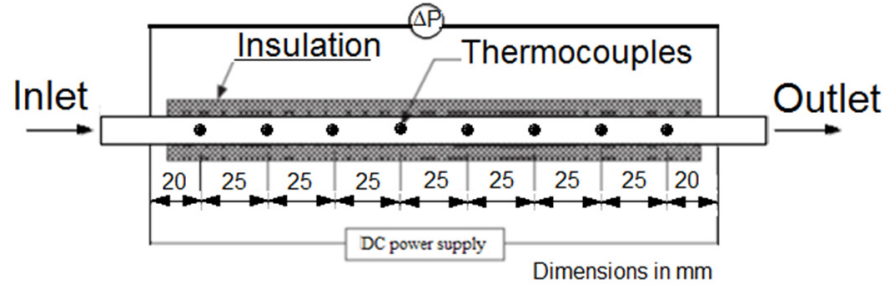

Figure 1: Schematic of the test section [9]. 


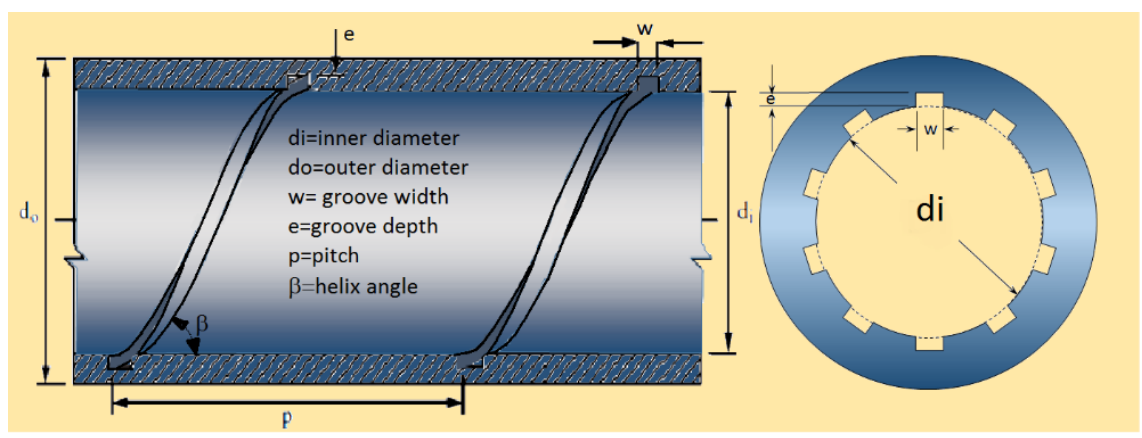

Figure 2: Sketch of tube showing grooved tube terminology [9].

\section{Numerical study}

\subsection{Grid generation}

\subsubsection{Grid generation for SMT}

Since the flow was simple in terms of geometry, 2D axisymmetric geometry and a fully developed turbulent profile as given in [10] was taken. The grid was generated in Gridgen v15.17 by Pointwise Inc. The mesh was clustered near the walls to resolve the boundary layer gradients adequately. The first cell height was with respect to $\mathrm{y}^{+}<1$ and kept equal to $5 \times 10^{-3} \mathrm{~mm}$. The mesh contained 139,676 cells.

\subsubsection{Grid for a straight groove tube}

The mesh for the analysis was created in the Gridgen v15.1. One quarter of the front end was modelled and then extruded all the way long into the third dimension. The plane consisted of 3 starts in total with the third being modelled as half-half being on the two symmetry planes. In experiment, for the straight groove case they are 12 along the periphery of the tube. The domains were modeled so that the cells near the wall remain intact with the first cell height in accordance with the $y+\sim 1$. The grid is shown in Figure 3. The mesh contained 32 blocks with 568,755 cells.

\subsubsection{Grid generation for helical groove tube}

The GT12 geometry has the nomenclature that means it is a groove tube with a pitch of 12 inches and that is equal to $305 \mathrm{~mm}$ as mentioned in [9]. The tube had the same outer diameter of $9.5 \mathrm{~mm}$ and the inner diameter of $7.1 \mathrm{~mm}$. Helical angle was 4.2 degrees. The number of starts were 10. The mesh was created with the similar logic as in the literature by Liu and Jensen [6] and Kim et al. [7]. Groove width was 1 and depth was $0.2 \mathrm{~mm}$. Helix angle was 4.2 degrees. A sector consisting of a 36-degree segment was constructed by taking advantage of periodic 


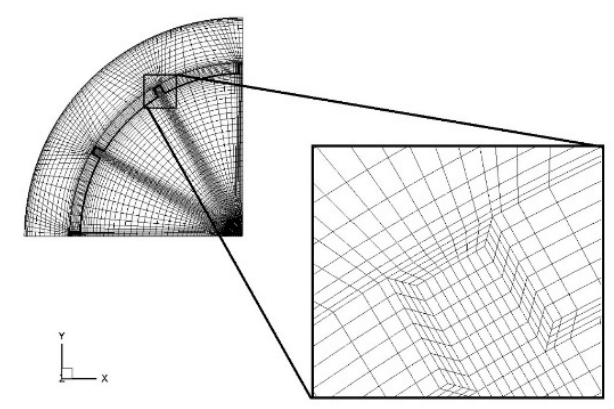

Figure 3: Front view of the grid on the straight grooved tube geometry, the grid in the start region has been enlarged in sub-figure for mesh clarity.

boundary conditions. This gave some liberty in making the mesh denser. However, there was still some boundedness due to limited computational resources. The mesh consisted of interface region between the solid and fluid domains that were created previously in case of straight tube and the plain tube. It contained 173,664 cells in the fluid region while 76,680 cells in the solid block. This is shown in Figure 4 . The portion of the region along the length of the tube where thermocouples were mounted and across which the pressure was measured was modeled for this simulation.

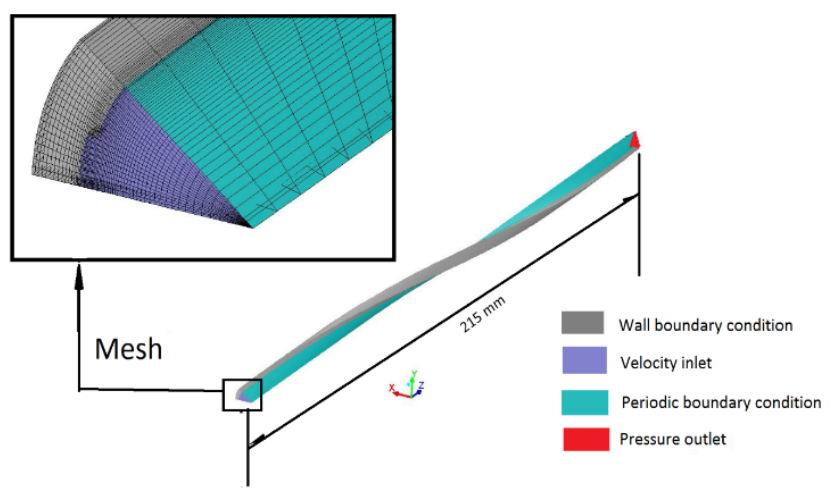

Figure 4: Mesh created for GT12 geometry.

\subsubsection{Boundary conditions}

The boundary conditions were after being named in Gridgen, physically given values in the solver. The solver used in the present case was ANSYS Fluent v16. The fluid used was liquid water whose physical properties were taken at the same temperature as with which experiment was performed, i.e. $298.15 \mathrm{~K}$. The properties of steel MS 304 were also taken at the same temperature. 
Axial velocity was input as turbulent velocity profile mentioned in [10] as a user-defined function. The turbulent intensity was computed using the guideline from Fluent manual [11]. It was computed using the following formula

$$
T . I=16 \mathrm{Re}_{\mathrm{D}}^{-1 / 8}
$$

Flux value of $3500 \mathrm{~W} / \mathrm{m}^{2}$ was applied on the top wall while interface had to be created between the solid and fluid regions.

\subsubsection{Turbulence models}

The range of flow Reynolds number based on the internal diameter were in turbulent regime as mentioned by the standard pipe flow literature like [10]. This allowed to use the turbulence models available in Fluent. Two turbulence models were used for determining the friction factor as well as Nusselt number inside the plain tube.

3.1.5.1 The k- $\varepsilon$ turbulence model The $k-\varepsilon$ turbulence model has been widely used turbulence model. It solves the basic transport equation for turbulent kinetic energy and the dissipation.

The realizable k- $\varepsilon$ contains a formulation for turbulent viscosity and another transport equation for the dissipation rate, which was derived from the exact equation for the transport of the mean square velocity fluctuation. "Realizable" means that the model satisfies certain mathematical constraints on the Reynolds stresses consistent with the turbulent flow physics.

3.1.5.2 The k- $\omega$ shear stress transport model The $k-\omega$ shear stress transport (SST) model is basically a blend of k-epsilon standard and the near wall k-w standard model. It takes advantage of this blending to resolve near wall gradients through the in-built wall functions, whereas solve the k-epsilon in the outer wall region.

\subsubsection{Discretization scheme}

In Fluent, the SIMPLE algorithm of Patankar was applied. SIMPLE stands for Semi Implicit Pressure Linked Equations. All the basic quantities namely, the pressure, velocity were used to obtain momentum, turbulence quantities and energy were using $2^{\text {nd }}$ order upwind scheme. The gradients were resolved using the least square cell based scheme.

Convergence criteria was monitored for residuals of continuity, $\mathrm{x}, \mathrm{y}$ and $\mathrm{z}$ velocities, turbulence quantities and energy equations. The criteria was not fixed and hence iterations were stopped manually when the monitors for pressure drop and velocity at outlet have no change in their magnitudes for at least a hundred iterations. Mass imbalance between velocity inlet and pressure outlet was also confirmed to be zero before stopping iterations.

All the cases were run on 4 cores of Intel Core i7 eight core processor with 16 Gb RAM. Each Reynolds number took around 1 hour with convergence in about 4000 iterations. 


\section{Results}

\subsection{Friction factor}

\subsubsection{Simple metallic tube}

The two models were selected for our case of turbulent flow through pipe. It can be seen in Figure 5 that k- $\omega$ SST is much closer to the experiment. Although the $\mathrm{k}-\varepsilon$ was also a good candidate but the reason of moving away from experiment is due to its better functioning in case of high Reynolds numbers [12].

The comparison of friction factor was also done with the analytical functions. These are the Blasius [13] and the Colebrook [14] and are mentioned in Eqs (2) and (3) respectively.

$$
f=0.316 \mathrm{Re}^{-1 / 4}
$$

and

$$
1 /(f)^{0.5}=-2.0 \log \left(\left(\varepsilon / d_{i}\right) / 3.7+2.5 /(\operatorname{Re} \sqrt{f})\right)
$$

Friction factor was obtained with the following formula

$$
f=\Delta p d_{i} /\left(0.5 L \rho V^{2}\right)
$$

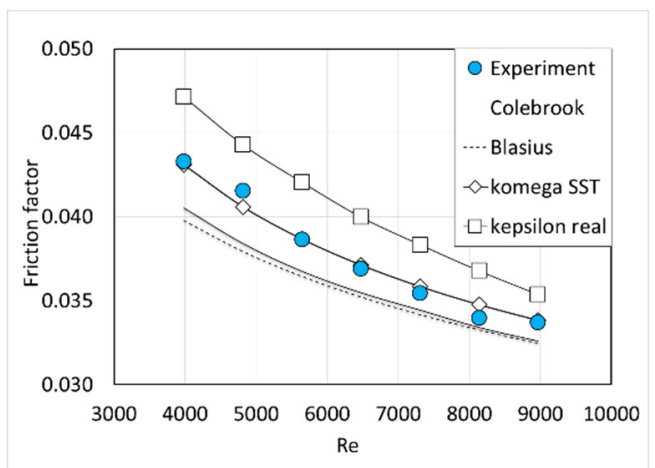

Figure 5: Comparison of the two turbulence models for Friction factor comparison for SMT.

\subsubsection{Straight grooved-tube}

The results were compared with experiment for both friction factor as well as the Nusselt number. Figure 6 shows the plot of friction factor. The results are in good agreement with the experimental findings.

\subsubsection{Groove tube with a 12-inch pitch (GT12)}

The results for friction factor are shown in Figure 7. The comparison shows that k- $\omega$ SST has a good comparison with experiment. However, the k- $\varepsilon$ realizable has over prediction than experiment. The difference is not much flickering in case of the plain pipe and Straight groove tubes due to the simplistic and streamlined flow. This deviation is prominent due to the swirling flow caused by the helical groove. 
This means that k- $\omega$ SST had successfully resolved the boundary layer flow, additionally, since the k- $\varepsilon$ is originally designed for high Reynolds number flows the trend of decreasing the difference from experiment reveals that this models would match the experiment values at higher Reynolds numbers. Unfortunately, the experimental data was limited to Reynolds up to 10000.

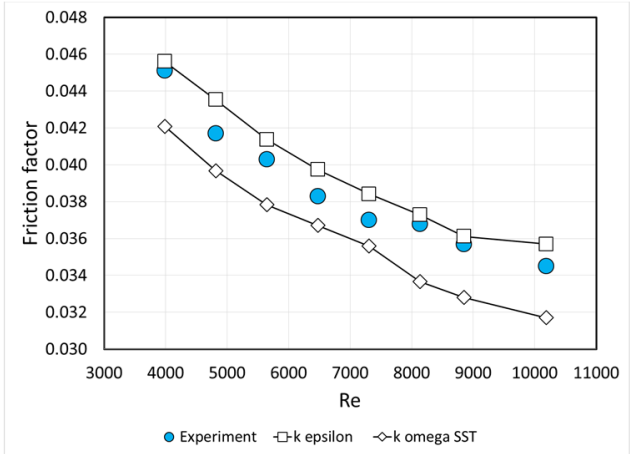

Figure 6: Friction factor results comparison with the experimental data for SGT.

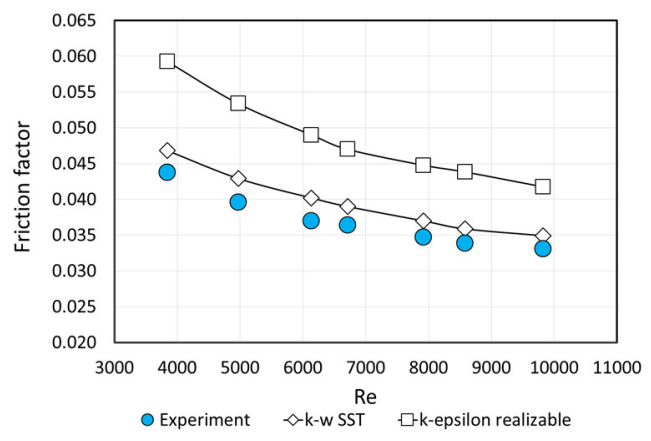

Figure 7: Comparison of the two models for friction factor in GT12.

\subsection{Nusselt number}

The Nusselt number was computed using the formula

$$
N u=h_{\text {avg }} d_{i} / k
$$

where $h$ computed as

$$
h_{\text {avg }}=\dot{q} /\left(T_{\text {avg.wi }}-T_{\text {avg }, f}\right)
$$

where, $T_{\text {avg,wi }}$ is the average temperature of the inner wall, $T_{\text {avg,f }}$ is the bulk-average temperature of water or mass-weighted average. The results of Nusselt number from experiment had an uncertainty of $618 \%$ that was added while plotting the curve. 


\subsubsection{SMT}

The CFD results are in good agreement with experiment for k- $\omega$ SST as shown in Figure 8. The curve for k- $\omega$ SST lies much nearer to the experiment depicting the actual physics of the phenomenon with an average error within $10 \%$. K- $\varepsilon$ performance was not good in depicting this simple flow. The Dittus and Boelter [15] and Gnielinski [16] equations are mentioned in Eqs. (7) and (8) respectively and are given in Figure 8 for comparison.

$$
\begin{gathered}
N u=0.023 \operatorname{Re}^{0.8} \operatorname{Pr}^{0.4} \\
N u=0.125 f(\operatorname{Re}-1000) \operatorname{Pr}\left(1+1.27(f / 8)^{0.5}\left(\operatorname{Pr}^{0.5}-1\right)\right)
\end{gathered}
$$

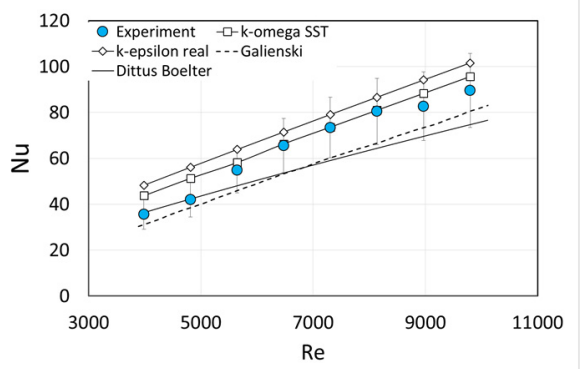

Figure 8: Nusselt number comparison with experiment and Dittus and Boelter [15] and Gnielinski [16] equation.

\subsubsection{SGT}

The graph of Nusselt number is shown in Figure 9. It is also in good agreement with the experimental data. Somewhat larger value of $\mathrm{Nu}$ is predicted by $\mathrm{k}-\varepsilon \mathrm{SST}$ at 8563 which could be a numerical artifact. Overall, the errors for the two models are within $10 \%$. And within the uncertainty limits of experiment.

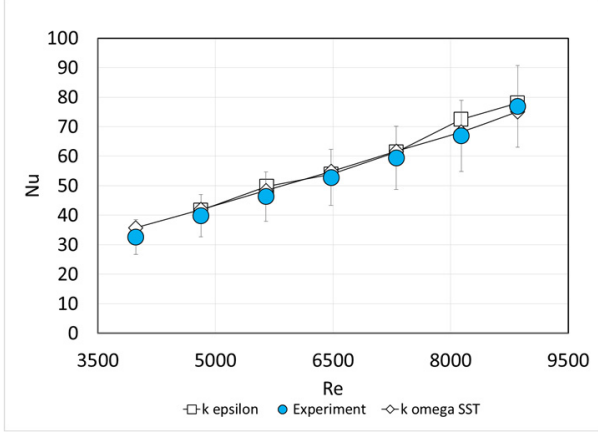

Figure 9: Nusselt number comparison with experimental data for SGT. 


\subsubsection{GT12}

If we compare the results of Nusselt number performance, the two models do not differ much from each other irrespective of the behavior in case of friction factor. It means that the nature of the models used is independent of the thermal effects. It is a good indication that the uncertainty limit of $618 \%$ mentioned in the literature for experimental results supports the CFD results that lie within the limit of this range. The results for the Nusselt number are shown in Figure 10.

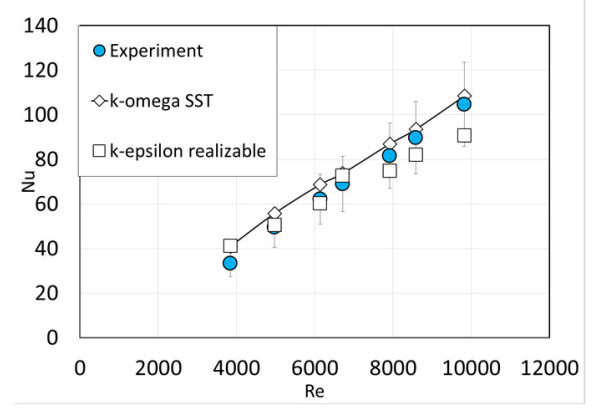

Figure 10: Nusselt number curve for GT12 and comparison of the two models.

\subsection{Thermal performance factor}

The thermal performance factor was computed using the relation

$$
\eta=\frac{\left(N u / N u_{s}\right)}{\left(f / f_{s}\right)}
$$

where the subscript ' $s$ ' is for smooth tube. This correlation helps in determining the effective heat transfer performance for grooved tubes. The curves obtained for the two tubes, namely, the straight groove tube and the groove tube with $305 \mathrm{~mm}$ pitch is shown in Figure 11. In the above discussion, since the performance of the $\mathrm{k}-\varepsilon$ model was not satisfactory overall, thus the results for thermal performance

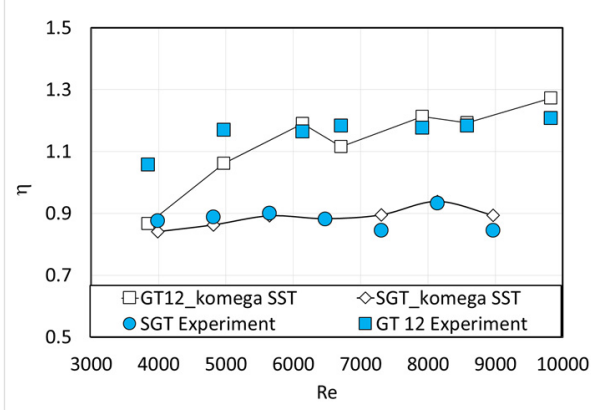

Figure 11: Thermal performance factor for SGT and GT12. 
factor is only shown for k- $\omega$ SST model. The curve shows that the GT12 tube has better performance as compared to the straight groove tube. In the experiment too, the same trend has been reported. This shows that SGT should not be recommended for heat exchanger applications. Although, the groove tube with a 12-inch pitch has better performance, the advantage can be increased further. This can be done by either changing the dimension of the grooves or by decreasing the axial pitch.

\section{Conclusion}

A set of three tubes, namely, simple metallic tube (SMT), the straight groove tube and the groove tube with 12 -inch pitch were numerically studied. Performance criteria was based on the heat transfer via Nusselt number as well as the friction factor. Numerically, the performance was evaluated on the basis of turbulence models, while for the heat transfer performance, it was evaluated with the thermal performance factor. Between the two turbulence models tested and the given range of Reynolds number, it was found that $\mathrm{k}-\omega \mathrm{SST}$ is the most suitable candidate for this range of Reynolds number due to its closeness to the experimental data. Among the three tubes tested and making the SMT the baseline, the GT12 performed better and has $\eta$ better at most of the Reynolds numbers.

\section{Acknowledgement}

The authors would like to acknowledge the institute for providing the computational facility of the PNEC of the National University of Sciences and Technology for performing this work.

\section{References}

[1] Ralph Webb and Nae-Hyun Kim, Principles of Enhanced Heat Transfer, 2nd ed. CRC Press, 2005.

[2] R. L. Webb, E. R. G. Eckert and R. J. Goldstein, "Heat Transfer and Friction Factor in Tubes with Repeated Rib Roughness," Int J Heat Mass Transf., vol. 14, pp. 601-6070, 1971.

[3] Michael K. Jensen and Alex Vlakancic, "Experimental investigation of turbulent heat transfer and fluid flow in internally finned tubes," Int. J. Heat Mass Transf., vol. 42, pp. 1343-1351, 1999.

[4] R. L. Webb, R. Narayanamurthy and P. Thors, "Heat Transfer and Friction Characteristics of Internal Helical-Rib Roughness," J. Heat Transf., vol. 122, pp. 130-142, Feb. 2000.

[5] Gregory J. Zdaniuk, Louay M. Chamra, and Pedro J. Mago, "Experimental determination of heat transfer and friction in helically-finned tubes," Exp. Therm. Fluid Sci., vol. 32, pp. 761-775, 2008. 
[6] Xiaoyue Liu and Michael K. Jensen, "Geometry Effects on Turbulent Flow and Heat Transfer in Internally Finned Tubes," J. Heat Transf., vol. 123, December, pp. 1035-1044, 2001.

[7] Je-Hoon Kim, Kenneth E. Jansen, and Michael K. Jensen, "Analysis of Heat Transfer Characteristics in Internally Finned Tubes," Numer. Heat Transf. Part Appl., p. 21, 2004.

[8] Piotr Jasinski, "Numerical optimization of flow-heat ducts with helical micro-fins, using Entropy Generation Minimization (EGM) method," in Recent Advances in Fluid Mechanics and Heat \& Mass Transfer, Florence, Italy, 2011, pp. 47-54.

[9] K. Aroonrat, C. Jumpholkul, R. Leelaprachakul, A. S. Dalkilic, O. Mahian, and S. Wongwises, "Heat transfer and single-phase flow in internally grooved tubes," Int. Commun. Heat Mass Transf., vol. 42, pp. 62-68, Mar. 2013.

[10] Bruce R. Munson, Alric P. Rothmayer, Theodore H. Okiishi, Wade W. Huebsch, Fundamentals of Fluid Mechanics, Fourth. John Wiley.

[11] “ANSYS Fluent Guide.” ANSYS Inc, 2014.

[12] David C. Wilcox, Turbulence Modelling for CFD. DCW Industries, Inc., 1994.

[13] P.R.H. Blasius, "Das Aehnlichkeitsgesetz bei Reibungsvorgangen in Flüssigkeiten, Forschungsheft," vol. 131, pp. 1-41, 1913.

[14] C.F. Colebrook, "Turbulent flow in pipes with particular reference to the transition region between smooth and rough pipe laws," J. Inst. Civ. Eng., vol. 11, pp. 133-156, 1939.

[15] F.W. Dittus and L.M.K. Boelter, "Heat transfer in automobile radiators of the tubular type," vol. 2, pp. 443-461, 1930.

[16] V. Gnielinski, "New equations for heat and mass transfer in turbulent pipe and channel flow," vol. 16, pp. 359-368, 1976. 